\title{
A CASE OF MOSAIC TRISOMY 14 DUE TO AN ISOCHROMOSOME, i $(14 q)$
}

\author{
Nobuyoshi Ozawa, ${ }^{1, *}$ Zhi-Da Xu, ${ }^{1, * * *}$ Kan-ichi SoH, ${ }^{1}$ \\ Toshifumi Takabayashi, ${ }^{1}$ Shinji Sato, ${ }^{1}$ Akira Yajima, ${ }^{1}$ \\ Masakuni SuzUKI, ${ }^{1}$ Tatsuro IKEUCHI, ${ }^{2}$ and Akira TonOMURA ${ }^{2}$ \\ ${ }^{1}$ Department of Obstetrics and Gynecology, Tohoku University School \\ of Medicine, Sendai 980, Japan \\ ${ }^{2}$ Department of Cytogenetics, Medical Research Institute, Tokyo Medical \\ and Dental University, Tokyo 113, Japan
}

\begin{abstract}
Summary A malformed male infant showed a mosaic trisomy 14 with a karyotype of mos $46, \mathrm{XY} / 46, \mathrm{XY},-14,+\mathrm{i}(14 \mathrm{q})$. The mosaicism was found both in peripheral blood cultures and in lymphoblastoid cells transformed by EB virus infection. His clinical picture was compared with those of 5 previously reported cases of trisomy 14 mosaicism, and the following common phenotypic features were noted: growth retardation, psychomotor delay, narrow or asymmetrical palpebral fissures, broad nose, low-set and dysplastic ears, high-arched palate, micrognathia, short neck, congenital heart disease, and undescended testes.
\end{abstract}

\section{INTRODUCTION}

A complete trisomy for the chromosome 14 has been detected in spontaneous abortuses (Kajii et al., 1972; Creasy et al., 1976), but never in newborns. However, trisomy 14 in a mosaic form with normal diploid cells and partial trisomy 14 have occasionally been reported in liveborn individuals ( $c f$. , Miller et al., 1979; Johnson et al., 1979). To date, only 5 cases of mosaic trisomy 14 have been described (Rethoré et al., 1975; Martin et al., 1977; Johnson et al., 1979; Turleau et al., 1980; Jenkins et al., 1981). In this paper, we report another case of this anomaly owing to a de novo formation of an isochromosome for the long arm of No. 14.

Received December 5, 1983; revised version received January 19, 1984

* To whom correspondence and reprint request should be addressed.

** Present address: Department of Histology and Embryology, Xu Zhou Medical College, Huai-Hai Road, the City of Xu Zhou, Jiangsu Province, The People's Republic of China. 


\section{CASE REPORT}

The patient was born to a 28 -year-old mother and a 30-year-old father. Both parents were in good health, and the family history was unremarkable. The patient had a 3-year-old healthy sibling. The mother has received neither radiation exposure nor cytotoxic drug around the time of the pregnancy. Pregnancy was complicated by toxemia and polyhydroamnion. The patient was delivered with cesarean section because of fetal distress at 39 weeks' gestation. His birth weight was 2,200 g, height $42 \mathrm{~cm}$, head circumference $31.5 \mathrm{~cm}$, and Apgar scores of 5 and 7 at 1 and $5 \mathrm{~min}$, respectively. At birth, he showed cyanosis, apnea and bradycardia. The following

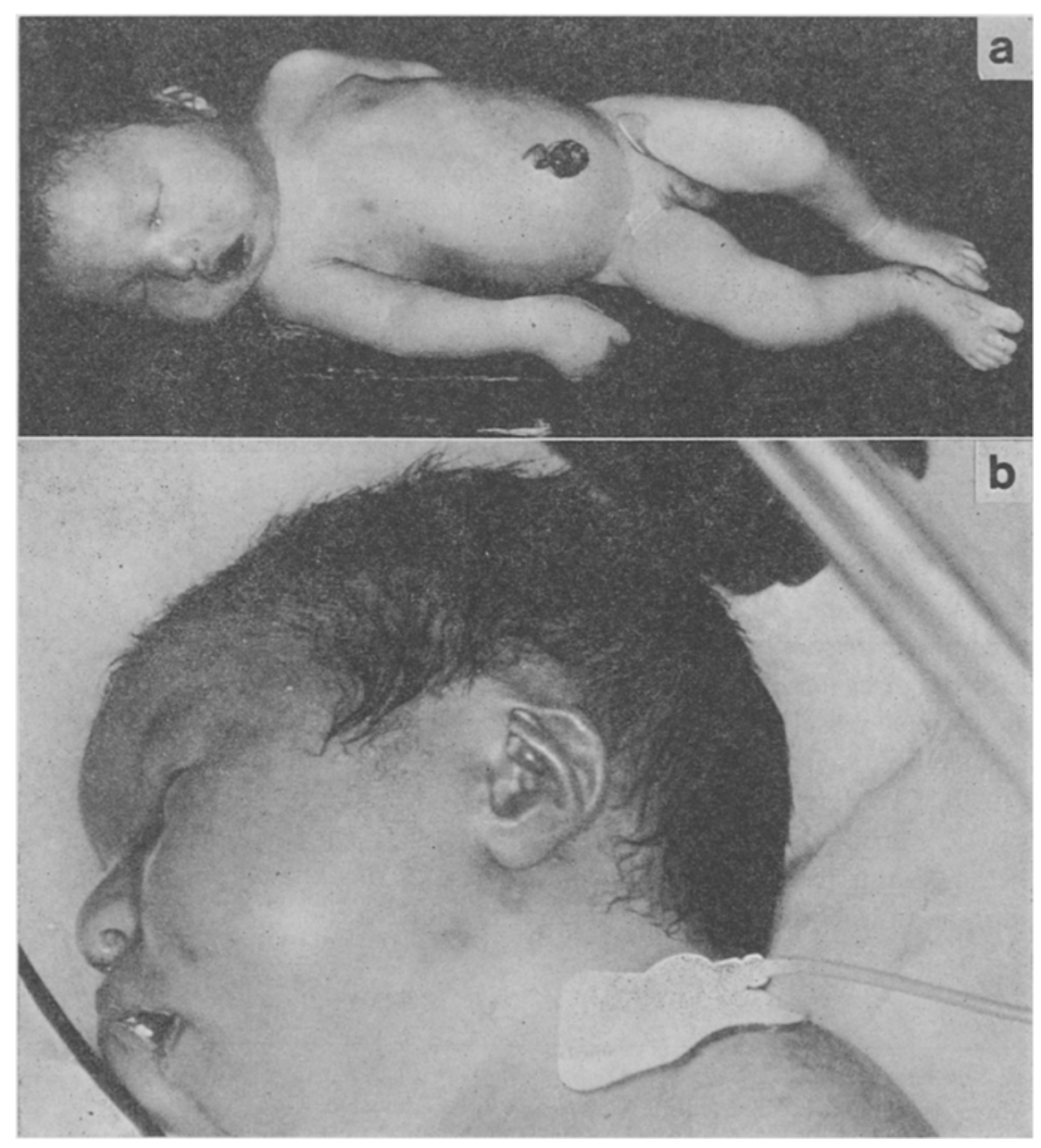

Fig. 1. Frontal (a) and lateral (b) views of the patient.

Jpn. J. Human Genet. 
physical anomalies were noted (Fig. 1): microcephaly, microphthalmus, narrow palpebral fissures, ptosis, micro-retrognathia, high-arched and cleft palate, low-set and dysplastic ears; short neck, clinodactyly of fifth fingers, hand flexion contracture; undescended testes, small penis; pansystolic heart murmur, and rale in pulmonary area.

He died of pulmonary bleeding at 12 days of life. The autopsy disclosed the following findings (Fig. 2): hypoplasia of cerebellum, hypoplasia of thymus (4g); incomplete ectopia cordis in the left thoratic cavity due to a large defect of pericardial sac, membranous ventricular septal defect, patent foramen ovale, narrow patent ductus
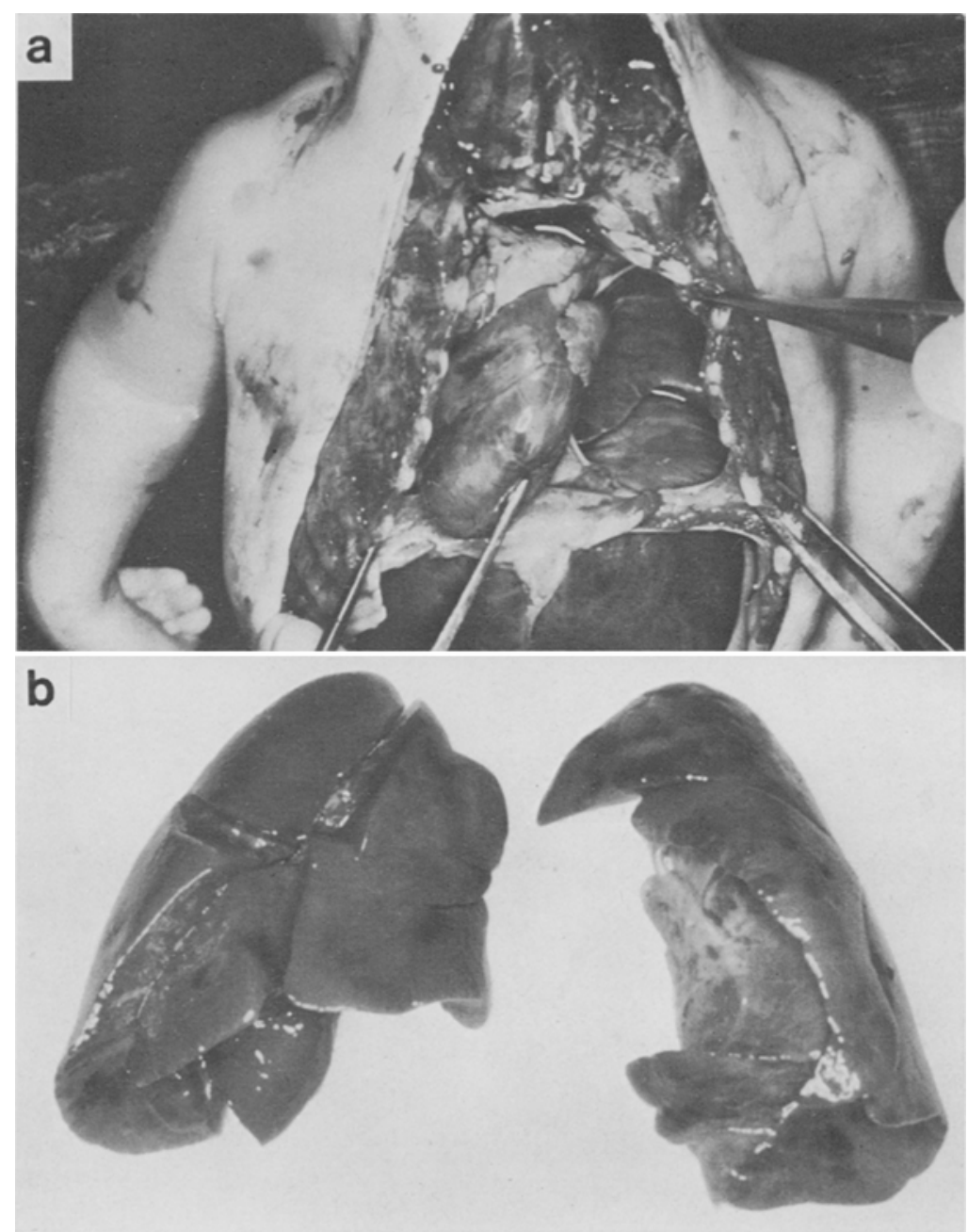

Fig. 2. Autopsy findings. Note a defect of the pericardial sac (a), hemorrhagic foci in bilateral lungs (b), and compression of the left lung due to ectopia cordis (b). 


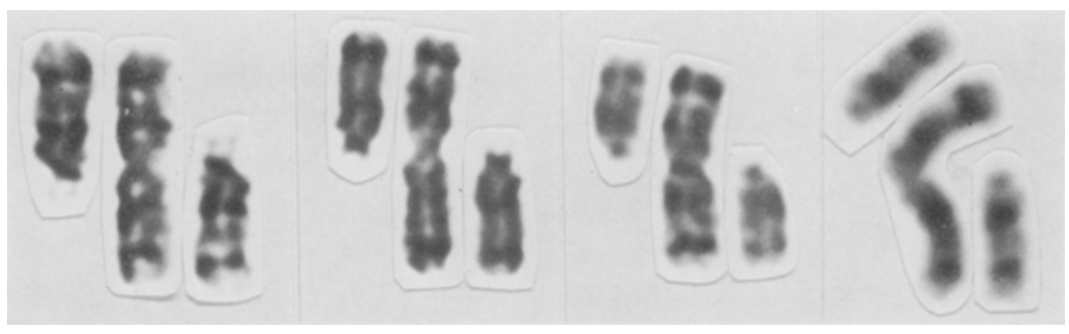

Fig. 3. G-banded No. 14 chromosomes in 4 different cells from the patient. For comparison, the normal No. 14 chromosomes are arranged along the both arms of $\mathrm{i}(14 \mathrm{q})$.

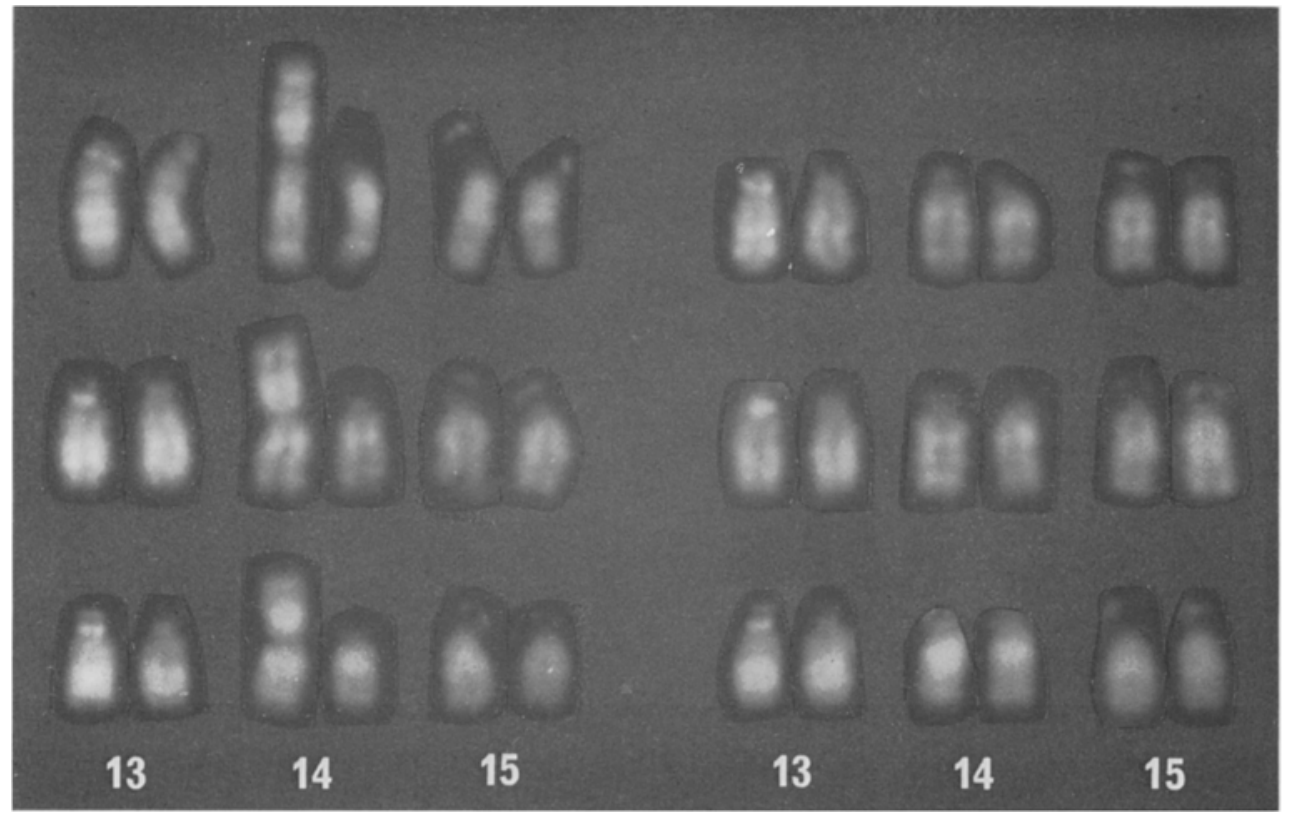

Fig. 4. Partial Q-banded karyotypes of the trisomic (left) and normal (right) cells from the patient.

arteriosus, cardiomegaly with dilatation of the left ventricle; abnormal lobulation (3 lobules) of the left lung, hemorrhagic foci in bilateral lungs with alveolar dysplasia, compression of the left lung due to the ectopia cordis; solitary subcapsular cyst (thumb tip-sized) of liver, partial malrotation of intestine showing mobile cecum, persistence of vitelline duct, hypoplasia of bilateral adrenal glands $(1 \mathrm{~g}, 1 \mathrm{~g})$, and irregular development of renal lobules. 


\section{CYTOGENETIC FINDINGS}

Chromosome studies of lymphocyte cultures were performed on two occasions shortly after birth of the patient. A total of 41 consecutive metaphases were examined. Of these, 12 cells $(29 \%)$ had a karyotype showing a missing element in the D-group, which was replaced by an extra large metacentric equivalent in shape to the No. 3 chromosome. The remaining 29 cells $(71 \%$ ) had a normal male karyotype. Skin fibroblasts were not examined. Both parents were karyotypically normal in cultured lymphocytes.

Chromosome banding studies of the patient were made using the lymphoblastoid cell line which was prepared from peripheral lymphocytes by transformation with Epstein Barr virus (EBV). With the G- and Q-staining methods, the missing element in the D-group was identified as a No. 14, and the large metacentric marker was found to be an isochromosome for the long arm of No. 14 (Figs. 3 and 4). Furthermore, Q-banding analyses demonstrated that the normal and trisomic cells showed the same types of heteromorphic chromosomes: one No. 13 showed a bright fluorescent centromeric region and both members of No. 15 had relatively large satellites (Fig. 4). This seems to suggest the monozygotic origin of the 2 cell lines, excluding the possibility of chimerism. The patient's karyotype was thus described as mos $46, \mathrm{XY} / 46, \mathrm{XY}$, $-14,+\mathrm{i}(14 \mathrm{q})$.

During the prolonged cultivation of the lymphoblastoid cell line, a drastic change

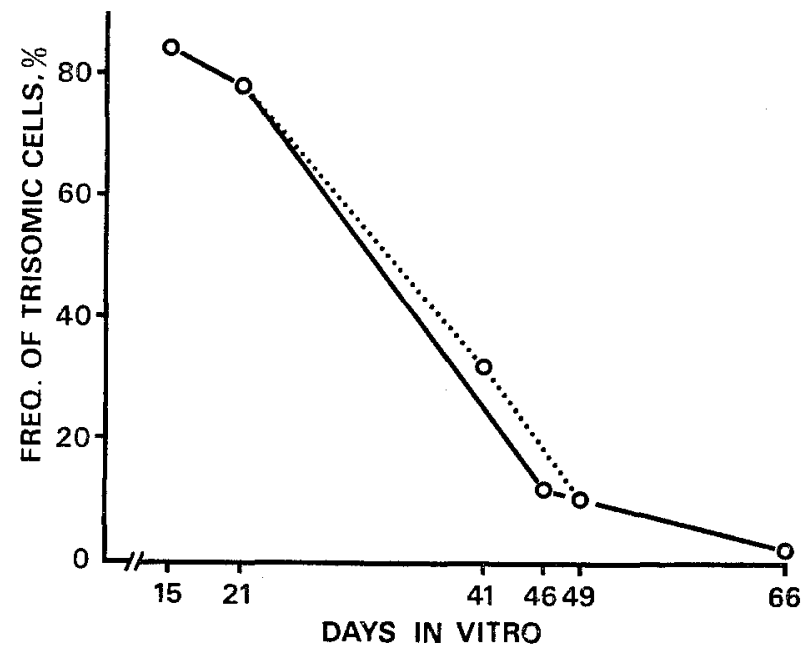

Fig. 5. Frequencies of trisomic cells in prolonged cultivation of the lymphoblastoid cell line. Solid line: the cell culture maintained continuously up to 2 months after transplantation. Dotted line: the culture recovered from the cells which had been frozen in liquid nitrogen on the 21 st day in vitro. 
in the frequency of cells with an $\mathrm{i}(14 q)$ was noted (Fig. 5). From $84 \%$ at the initial examination, the frequency of the abnormal cells decreased to merely $2 \%$ after 2 months. This same trend was observed in a separate culture recovered from the cells stored in liquid nitrogen.

\section{DISCUSSION}

Murken $e t$ al. (1970) had reported one child of presumptive non-mosaic trisomy 14 based on autoradiographic studies, but its identification remains uncertain without confirmation by banding analyses and studies in skin fibroblasts. Thus, non-mosaic complete trisomy 14 seems to be incompatible with the development to term of the fetus.

The reported cases of mosaic trisomy 14 include 3 cases with an additional chromosome 14 (Rethoré et al., 1975; Martin et al., 1977; Johnson et al., 1979) and 2 cases showing the trisomy resulting from formation of an isochromosome (14q) as seen in the present case (Turleau et al., 1980; Jenkins et al., 1981). Phenotypic observations of our case and 5 other patients with mosaic trisomy 14 revealed the following clinical similarities (Table 1): growth retardation, psychomotor delay, microcephaly, asymmetrical or narrow palpebral fissures, ptosis, wide and flat nose, low-set and dysplastic ears, high-arched palate, micro-retrognathia, short neck, fifth finger clinodactyly, and congenital heart defect. These features may represent the common major characterization of the trisomy 14 mosaicism. Some of the patients showed other anomalies, such as wide mouth, hypertelorism, hand flexion contracture and dislocation of the hip joint. Four of 6 cases were female, and 2 male cases including the present case had undescencied testes. Our case was only an example in which autopsy was performed, and revealed some specific gross internal malformations, including a defect of pericardium and abnormal lobulation of the lung.

The EBV-transformed cell line yielded some interesting chromosomal findings. The frequency of the trisomic cells immediately after transformation was as high as $84 \%$, in contrast with $29 \%$ in PHA-stimulated lymphocyte cultures. This may indicate the intrinsic difference in the frequency between the B- and T-cell populations, the former being transformed by EBV and the latter grown in the presence of PHA. However, it cannot be ruled out that the trisomic cells might be more susceptible to EBV-transformation or that there might be a selective advantage in vitro of trisomic cells during the transformation process. The latter possibility, however, seems to be incompatible with the finding that the trisomic cells were rapidly eliminated from the cultures during the subsequent maintenance of the cell line. A similar instability of trisomic cells in vitro has occasionally been observed in fibroblast cultures derived from various mosaic cases (Ikeuchi and Sasaki, 1975; Niss and Passarge, 1976), though such a trend is not necessarily generalized in all the cases of mosaicism (Chang et al., 1969; Taysi et al., 1970).

It is frequently argued that the cell population in cultures may not necessarily 


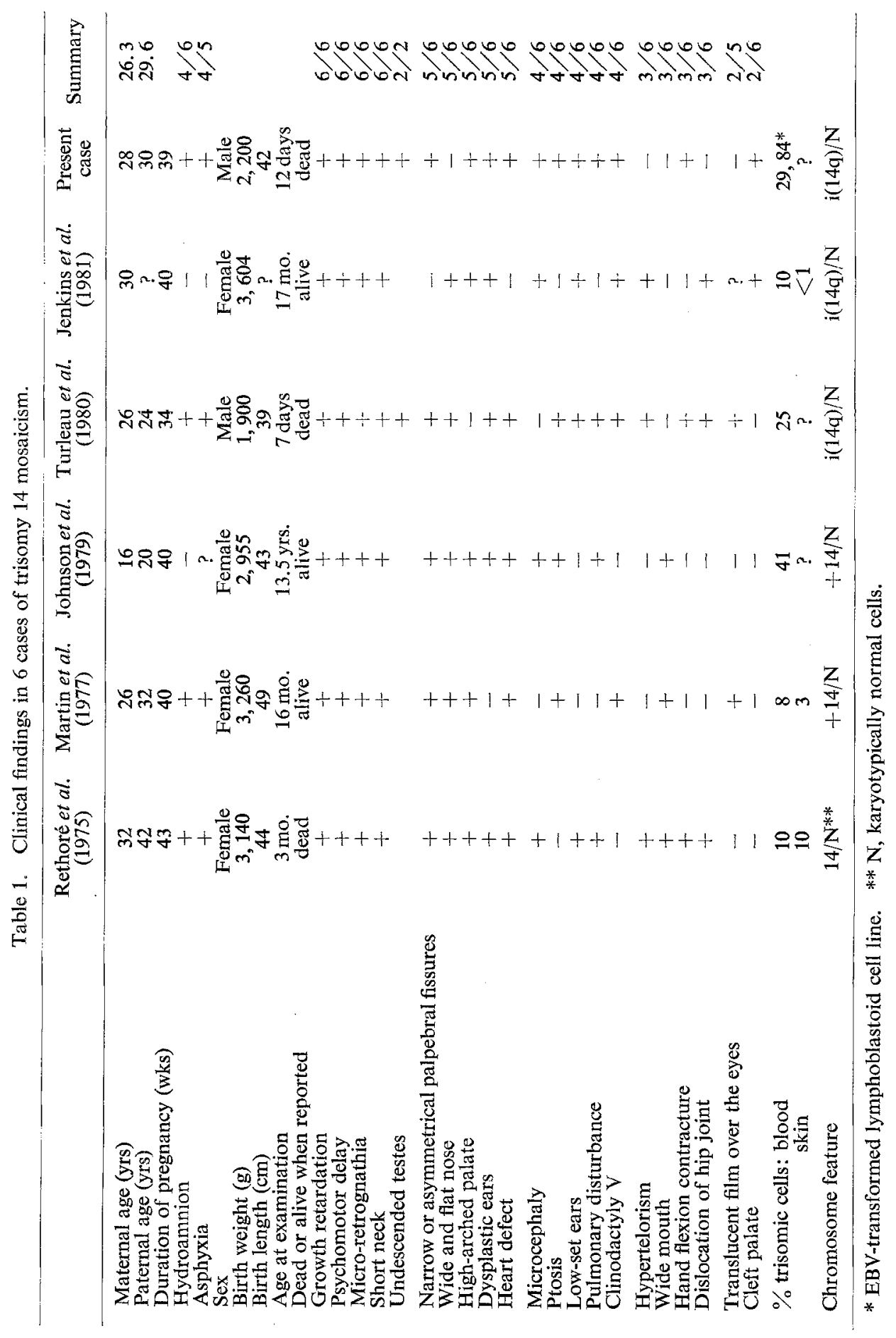

Vol. 29, No. 1, 1984 
reflect the true status of mosaicism in vivo, and that there may be a quite different proportion of abnormal cells among different tissues or cell types. As shown in Table 1 , there is no positive correlation between the percentages of the trisomic cell line and severity of the clinical features.

Acknowledgements We are indebted to Dr. Hiroko Tohda of Department of Pharmacology, Research Institute for Tuberculosis and Cancer, Tohoku University, for helpful suggestion in preparing the lymphoblastoid cell line, and Miss Noriko Miyashita for her excellent technical assistance.

\section{REFERENCES}

Chang, T.D., Niewczas-Late, V., and Uchida, I.A. 1969. Selection for trisomic cells in a mosaic fibroblast culture. Cytogenetics 8: 410-414.

Creasy, M.R., Crolla, J.A., and Alberman, E.D. 1976. A cytogenetic study of human spontaneous abortions using banding techniques. Hum. Genet. 31: 177-196.

Ikeuchi, T., and Sasaki, M. 1975. An abortus with a normal/trisomy 16 mosaicism: Instability of trisomic cells in vitro. Humangenetik 30: 167-171.

Jenkins, M.B., Kriel, R., and Boyd, L. 1981. Trisomy 14 mosaicism in a translocation 14q15q carrier: Probable dissociation and isochromosome formation. J. Med. Genet. 18: 68-71.

Johnson, V.P., Aceto, Jr., T., and Likness, C. 1979. Trisomy 14 mosaicism: Case report and review. Am. J. Med. Genet. 3: 331-339.

Kajii, T., Ohama, K., and Ferrier, A. 1972. Trisomy 14 in spontaneous abortus. Humangenetik 15: $265-267$.

Martin, A.O., Ford, M.M., Khalil, N.T., Turk, K.B., and Macintyre, M.N. 1977. 46,XX/47,XX, +14 mosaicism in a liveborn infant. J. Med. Genet. 14: 214-233.

Miller, J.Q., Wilson, K., Wyandt, H., Jaramillo, M.A., and McConnell, T. 1979. Familial partial 14 trisomy. J. Med. Genet. 16: 60-65.

Muiken, J.D., Bauchinger, M., Palitzsch, D., Pfeifer, H., Suschke, J., and Haendle, H. 1970. Trisomie $\mathrm{D}_{2}$ bei einem $2 \frac{1}{2}$ jährigen Mädchen $(47, \mathrm{XX},+14)$. Humangenetik 10: 254-268.

Niss, R., and Passarge, E. 1976. Trisomy 8 restricted to cultured fibroblasts. J. Med. Genet. 13: 229-234.

Rethoré, M.O., Couturier, J., Carpentier, S., Ferrand, J., and Lejeune, J. 1975. Trisomie 14 en mosaique chez une enfant multimalformée. Ann. Génét. 18: 71-74.

Taysi, K., Kohn, G., and Mellman, W.J. 1970. Mosaic mongolism. II. Cytogenetic studies. J. Pediatr. 76: 880-885.

Turleau, C., de Grouchy, J., Cornu, A., Turquet, M., and Millet, G. 1980. Trisomie 14 en mosaïque par isochromosome dicentrique. Ann. Génét. 23: 238-240. 